\title{
Access Barriers to Health Services for Women Who Use Drugs in Eastern Europe and Central Asia
}

\author{
Daria Matyushina-Ocheret
}

This chapter is based on the author's 15 years of work with the Eurasian Harm Reduction Network and with the Eurasian Harm Reduction Association (EHRA) and including the European Commission funded project Strengthening the capacity of non-state actors in addressing the needs of women who use drugs in Eastern Europe (2012-2015), the regional campaign Women Against Violence (2013-2015) and a study of human rights violations among women who use drugs in Estonia (Kontautaite et al., 2018). This chapter also incorporates data generated by community-led research: a qualitative interview-based study of reproductive rights violations in St. Petersburg, Russia conducted by EHRA in 2018 (referred to as St. Petersburg study) and a mixed-methods study of the access of women who use drugs to sexual and reproductive health, HIV and harm reduction services conducted by the NGO Svitanok in areas near the conflict zone in Ukraine (referred to as $A S W A C$ ). The author would like to acknowledge the role of her colleagues Maria Plotko and Arune Kontautaite (EHRA) and Svitlana Moroz (NGO Svitanok) in the design of the studies, data collection and analysis. The author would like to express her gratitude to the women who have shared their stories that laid the foundation for this analysis of access barriers to health services in Eastern Europe and Central Asia (EECA).

\section{Data Gaps}

EECA is home to $21 \%$ of the world's population of people who inject drugs (UNAIDS, 2019b). According to the global systematic review published in 2017,

\footnotetext{
The Impact of Global Drug Policy on Women: Shifting the Needle, 75-83

Copyright $(\mathcal{C} 2021$ by Daria Matyushina-Ocheret

These works are published under the Creative Commons Attribution (CC BY 4.0) licence. Anyone may reproduce, distribute, translate and create derivative works of these works (for both commercial and non-commercial purposes), subject to full attribution to the original publication and authors. The full terms of this licence may be seen at http://creativecommons.org/licences/by/4.0/legalcode doi:10.1108/978-1-83982-882-920200012
} 
$25.4 \%$ of the approximately 3,020,000 of people who inject drugs (PWID) in Eastern Europe are women (Degenhardt et al., 2017). In Central Asia, the share of women is lower $-12.6 \%$ of a 281,500 total PWID population (Degenhardt et al., 2017). Most of these estimates are outdated. Country population size estimates for all Eastern Europe states are from 2012 or earlier. Data on the Russian Federation - the country that has the second largest PWID population in the world - are from 2007. Estimates for Central Asia dated from 2006, and no data is available for Turkmenistan (Degenhardt et al., 2017, p. 73). More up to date estimates for women who use drugs are missing in global and regional databases and reports, such as UNAIDS Data 2019 (UNAIDS, 2019a), UNAIDS Key Populations Atlas (UNAIDS, n.d.) and the European Drug Report (European Monitoring Centre for Drugs and Drug Addiction (EMCDDA), 2019a).

Population size estimates for women who use drugs are fundamental for service planning and evaluation as they provide the denominator for the downstream data analysis. In other words, we cannot evaluate if services are gender sensitive and reach an adequate number of women who use drugs. But the health status of women who use drugs in EECA is not totally unknown. Having the fastestgrowing HIV epidemic in the world (UNAIDS, 2019a), the region has genderdisaggregated data on key HIV indicators.

PWID account for $41 \%$ of new HIV cases in EECA and HIV prevalence in this group is $7.4 \%$ ranging from $1.9 \%$ in Armenia to $51.4 \%$ in Estonia (UNAIDS, n.d.). With few exceptions, HIV prevalence among women who inject drugs is significantly higher than among male PWID in EECA. UNAIDS database shows that in Georgia, Moldova, Tajikistan and Uzbekistan HIV prevalence among women who inject drugs was at least double than among men for the latest reported year. In Estonia, $61.5 \%$ of women and $47.9 \%$ of men who inject drugs have HIV; in Ukraine, respective figures are $31.4 \%$ and $20.7 \%$ (UNAIDS, n.d.).

Gender disaggregated data on sexual and reproductive health, viral hepatitis prevalence, treatment access, domestic violence and police brutality are not available for the majority of EECA countries making adequate planning, funding allocation and evaluation of gender-sensitive services almost impossible.

\section{Drug Registries}

In EECA states, structural barriers to harm reduction services are closely related to narkouchet, which is commonly referred to in English-language literature as a drug (treatment) registry. Storage and management of the information in drug registries is a function of narkodispansers - drug dispensaries, which combine the functions of drug prevention, treatment and registration of people who use drugs in the vast majority of EECA countries.

Drug registries were formed in the USSR in 1988 in accordance with Order \#402/109 of the Ministry of Health and the Ministry of the Interior (USSR Ministry of Health \& USSR Ministry of Internal Affairs, 1988). The primary goal of the order was to identify and register people that 'allowed non-medical use of narcotic and intoxicating drugs'. The order also requested organisation of mandatory drug treatment. An important feature of the order was that it required 
information sharing between law enforcement and health sectors about all persons suspected of drug use, and promoted the involvement of labour collectives and educational institutions in the identification of people who used drugs. The system was organised in such a way that it blurred the line between treatment and punishment and left no confidentiality of patient records.

Order \#402/109 formed the spirit of drug policies in all the post-Soviet states, in which surveillance and control continued to prevail over the public health approach long after the breakdown of the Soviet Union. Drug registries became the backbone of drug demand reduction strategies of EECA countries. They were used to analyse drug use trends, to report efficiencies and failures of drug prevention and to plan and fund services. In some cases, the proportion of women in drug registries was extrapolated to the whole population of women who used drugs, even though women had additional reasons to avoid getting in touch with this system. For women the inclusion in the drug registry would lead to the risk of limited parental rights, multiplying the negative effect of registration in drug dispensaries (Golichenko \& Chu, 2018).

An analysis of the effects of drug registration laws in Russia, Ukraine and Georgia conducted in 2009 summarised the consequences of drug registries in the following way: restriction of civil rights, marginalisation, violations of privacy and confidentiality of health information, increased vulnerability to police abuse and extortion, fear of seeking help and obstacles to obtaining healthcare and harm reduction services (Shields, 2009). This is still true today for EECA states even though the legal provisions in some countries underwent significant changes. Nowadays, drug registries in EECA claim to protect the confidentiality of patient records but recent research shows that even in EECA countries, which are European Union (EU) members, such as Estonia, drug treatment data leaks continue to be used against women, limit their parental rights and decrease their employment prospects (Kontautaite et al., 2018).

The Soviet drug registry order was fully repealed in Russia only in 2016 but the information about people who use drugs continued to be collected and stored by drug dispensaries. The majority of people who use drugs in Russia remain unaware that the law has changed. Russian web platform for pro-bono legal support for people who use drugs Hand-help.ru continues to get requests: 'I was arrested with drugs. Will they put me on the registry?' (www.hand-help.ru, n.d.). In fact, registries continue to exist with the same functions as before, but now the registration is voluntary on paper but still unavoidable if someone has been arrested with drugs. It is still required to bring proof from drug dispensaries that one's name is not included in the registry in order to get a driver's license or demonstrate suitability for certain jobs. In many big companies, the security services check the background of potential employers and the data from drug registries are taken into account.

For women being in a drug registry also plays a critical role in child custody. The following quotes derived from the interviews from EHRA St. Petersburg study show the effect of Order \#402/109 on Russian women's lives two years after it has been abolished:

Automatically, I am a dysfunctional mother because I am on the drug registry. 
My husband, by the way, filed a lawsuit against me, depriving me of parental rights, again, based on the fact that I was registered at the drug dispensary. He wanted to prove that I was a dependent person and deprive me of parental rights.

Unfortunately, it was very difficult to get a job with my past, because when you get a job, the security service checks it all. If a person is registered at a drug dispensary, all this information goes to a common database. I had the article 228, storage [of drugs] for personal use, a long time ago, 18 years ago.

Getting off the registry is possible but complicated and requires a lot of effort and money from women.

No one put me off the registry. I was told that you have to go through a psychologist and something else. To bring a certificate that I am registered at the AIDS center, that I am taking [HIV] therapy. I brought them this certificate, went through a check at psychologist, went through a check at drug treatment doctor and had an independent test, for a year, that I didn't have any drugs in my body. I paid money for it. I went there twice and handed over nails, tufts of hair.

Currently, the forms of narkouchet vary across the region from formal mandatory registration as in Belarus and voluntary registration in Russian to a rather informal practice of 'being known' to the police, health, social and child protection services in Estonia. The hardest and most tragic stories shared by women relate to the interplay between formal and informal narkouchet and the formal and informal policy of removing newborns and older children from mothers who use drugs. Among 103 women with children from the ASWAC study, 13 were denied child custody or had their parental rights limited. In the St. Petersburg study, eight women lost child custody and ten were at risk of losing their children at the time of interview. In Estonia, 25 cases were documented. There is no legal provision in Estonia that would require limitation or withdrawal of parental rights in the case of drug use (Kontautaite et al., 2018).

Both in Russia and Estonia child protection services use children as an instrument of pressure to make women undergo abstinence-based treatment. In neither Russia nor Estonia do detox or rehabilitation treatment centres allow babies or children to stay with their mother.

When they arrested me for drugs, child protection services immediately came and said that they would leave the child only if 
I go to [residential] rehabilitation. In general, there is no such law that they can pick up a child from me. They start: you are a drug addict, you have HIV. You exhale and understand that you have no options. In general, I was afraid to go there because the drug treatment hospital was scary. I went there crying. I didn't know what to do.

Being on the drug registry is an obstacle to social integration, but not being in the registry is a barrier to drug treatment. Women cannot get access to freeof-charge detox in Russia if they are not in the registry. In other countries they cannot get access to opioid substitution treatment (OST) as being on the registry is a requirement of OST eligibility.

So the decision that a woman needs to take lies between the following options: Shall I stay invisible to the system, get no drug treatment but have a chance to get a job and keep my children? Or shall I try drug treatment at the cost of being exposed to the state surveillance and the risk of not being able to find a job and losing custody of my children?

\section{Criminalisation}

Women who use drugs are a highly criminalised group in EECA. While drug use is not a criminal offence, threshold quantities of drugs are so low that the possession of a regular daily dose of heroin or amphetamine can lead to months or years of incarceration (EHRA, n.d.). De jure decriminalisation of the possession of small quantities of drugs that happened in some EECA countries did not lead to liberalisation. For example, in 2018 in Kyrgyzstan, the possession of small quantities of drugs was removed from the administrative code and became a misdemeanour, but fines for drug-related misdemeanour were so high that the financial burden was harder to manage than several months of incarceration (Bessonov, 2018).

Drug-related offences are one of the main causes of women's incarceration in EECA. For example, the WHRIN (2019) paper presented at the UN Commission on Narcotic Drugs says that up to $70 \%$ of incarcerated women in Tajikistan are there because of drugs. But criminalisation of drug use is not only about serving a prison sentence. Criminalisation shapes the everyday life of women who use drugs, making them choose paths where they could avoid or minimise contact with the police and to have lifestyles that would make them invisible to the system in order to protect their freedom.

In interviews conducted in St. Petersburg and East Ukraine, women describe how they are being stopped, searched and interrogated by the police based solely on their appearance. Interviewees say that their faces, hands, eye pupils make them different from normal people. They speak about the feeling of being wrong, disliked and insecure.

Maybe there is something wrong with my face but they arrest me all the time. 
Naturally, in my area, everyone [from the police] knows [me]. The police and every district officer knows who uses and who does not use.

Therefore, I try not to go by subway. I just don't feel like it again. They [the police] don't like my appearance, my documents are checked, looked at, inspected.

The study conducted in Estonia documented the following practice: the police recognised women as using drugs, stopped them and requested a saliva drug test. If the woman objected to the saliva test, she was taken to the police station for a urine drug test, which sometimes was conducted through a urinary catheter. In the case of a positive drug test result, women were required to pay the fine and also reimburse the cost of drug testing (Kontautaite et al., 2018).

Arbitrary arrest continues to be a big issue in EECA. At the same time, according to Russian and Estonian research participants' accounts, physical and sexual abuse by the police is less widespread than before.

They could just take me to the police station and hold me there until the morning. Not based on anything. Without any papers. Make me do the cleaning there. Or force me to have sex. Free of charge, of course. Thank god now it got better. There is no such lawlessness as before.

But the effects of police violence continue to shape women's attitude to the police and motivate the avoidance of contact with the state. Again, the institutional effect of criminalisation and stigma created by criminalisation lives long after a legislative change.

\section{Ignoring Women's Needs in Programme Design}

OST with methadone or buprenorphine is the main internationally recognised method of drug dependence treatment. In EECA, OST programmes are not available in Russia, Uzbekistan and Turkmenistan. In the majority of EECA countries of the region, the coverage of OST programmes is within 1.5-4.4\% (UNAIDS, n.d.). Ukraine, which is the regional leader in OST provision in absolute numbers with over 10,000 OST clients, reaches only $3.8 \%$ of PWID (UNAIDS, n.d.; World Health Organization (WHO), 2018). Georgia reports high coverage of OST showing a seven-fold increase since 2015 due to the elimination of user fees for OST (UNAIDS, 2019b). However, the number of women receiving OST didn't change, and the gender gap for OST remains enormous (M. Khmelidze, personal communication, November 14, 2019). In other non-EU countries of the region, the coverage of OST programmes is within 1.5-4.4\% (UNAIDS, n.d.). 
Specific women's needs are neglected in the design of EECA OST programmes. National drug treatment protocols require daily attendance of OST clinics. Daily morning visits to clinics are a barrier to education, vocational training and employment. But in the region where women still are the main family caregivers, this becomes almost an impossible condition for women, especially when they have young children. So there is again a choice between either receiving drug treatment or being able to work, study and take care of children or other family members. If this barrier was removed, OST would help women better integrate into society.

Another issue across EECA is that OST is not integrated with reproductive health services. In the Estonian study, none of the respondents received OST during their pregnancy (Kontautaite et al., 2018). Women preferred to hide their drug dependence from healthcare staff because they were afraid of losing custody of their newborn children (Kontautaite et al., 2018). The ASWAC study revealed eight cases when women were pressured to have an abortion because of their drug dependence (instead of being advised to start OST) and one case when doctors decided on the abortion because the woman was on OST. Those who gave birth while on OST faced negative attitudes from healthcare staff:

When I came to the maternity hospital, I had papers where on the front page it was even written that I was in the drug dispensary registry. On the second page there was a sticky note on how much methadone I take. They called the head doctor, and the drug treatment doctor, as if they faced this [methadone treatment] for the first time ... I heard the doctor called me 'methadone bitch'. They treated me like I am a drug addict .... They were very prejudiced towards me.

In Kazakhstan, where a pilot methadone programme was launched in 2008 , OST is still not available in maternity hospitals. This was included in the civil society shadow report to the Convention on the Elimination of all Forms of Discrimination Against Women (CEDAW) in 2018 but has not yet been addressed by the state. The shadow report developed by Kazakhstan communities of people living with HIV/AIDS (PLHIV) and key populations included a case description in which a woman was forced to undergo an abortion because of being on OST during the pregnancy (Kazakhstan Union of People Living with HIV et al., 2018). Only 58 women receive OST in Kazakhstan, and this number is not likely to grow in the near future (Kazakhstan Union of People Living with HIV et al., 2018).

\section{Harm Reduction and Linkage to Healthcare}

Needle syringe programmes (NSP) are the gold standard of harm reduction. While the statistics on the gender of NSP clients are routinely collected, the majority of EECA do not report to UNAIDS how many women access NSP. Three countries that do report - Moldova, Kyrgyzstan and Tajikistan - show slightly higher access rates among women than among men (UNAIDS, n.d.). At the same time, NSP is only one of nine interventions of the comprehensive 
package recommended specifically for people who inject drugs (WHO, 2016). So the question is whether women receive further access to health services through NSP, in other words - whether NSP helps to overcome healthcare barriers that have been created by drug registries, criminalisation and drug-related stigma.

The ASWAC study recruited 150 women who injected drugs or were OST clients through harm reduction programme staff. About $89.66 \%$ of women interviewed received community-led harm reduction services during the last 12 months and all of them were harm reduction programme clients at a certain point in time.

HIV testing rates were high - only 1 woman out of 150 participants had never been tested for HIV; and among 66 respondents who indicated that they were HIV negative, $84.85 \%$ were tested during the previous 12 months. HIV treatment rates were also high - only 3 out of 79 women living with HIV had never received antiretroviral treatment. However, if we look at their access to sexual and reproductive health services, we see very low rates: $39.33 \%$ of women had never been tested for sexually transmitted infections (STIs); $79.33 \%$ of respondents had never received any STI treatment; and 13 persons ( $8.6 \%$ of all respondents) reported self-treatment of STIs. Hepatitis C treatment rates were also very low: $91.86 \%$ of respondents who knew that they had hepatitis $\mathrm{C}$ had never been treated.

Why is access to HIV testing and treatment so much better than for hepatitis and STI services? Hepatitis C and STI treatment are rarely available free of charge. Only 10 of those who have ever been tested for STIs in the survey had their latest STI test for free, and all of those who received STI treatment always had to pay for it. Only one person received hepatitis $C$ treatment free of charge. When we look at the employment and income situation of women who participated in the study we can see that, even in cases of high motivation to access hepatitis C or STI treatment, they faced significant financial barriers. About $44.67 \%$ of respondents did not have enough money for food; $36.67 \%$ - enough for food, but not enough for clothes; and $17.33 \%$ - enough only for food and clothes. This makes user fees for STI and hepatitis C treatment and other kinds of health services unaffordable.

Poverty is a barrier to health services, and income is an important determinant of health. Poverty rates among people who use drugs are high globally, and barriers to stable income are again linked to drug-related stigma and criminalisation (Long et al., 2014). People who use drugs and women in particular often have lower educational attainment and this decreases employment chances (Long et al., 2014). However, the educational level among the Ukraine study respondents was relatively high, with over $60 \%$ having obtained professional or technical college and higher. But the unemployment rate at the time of the interview was $56.7 \%$, compared to $14.4 \%$ average in Donetsk region and $15.3 \%$ in Lugansk region, which are directly affected by the armed conflict (Graziosi, 2015).

Repressive drug policies, drug registries with consecutive deprivation of social rights and criminalisation explain why women with a relatively good educational background have such low income that almost half of them do not have enough money for food. In this economic context, out-of-pocket payments for health services - whether it is STI or hepatitis C treatment, drug treatment or any kind of basic health services - are unaffordable to them. Harm reduction services in many EECA states reach a sufficient number of women who use drugs to be able to 
significantly increase women's access to the full package of WHO-recommended services, but only if these services are provided free of charge.

EECA countries use various models of healthcare financing but in the majority, harm reduction programmes have originally been funded by international donors and are still not integrated into national health systems. In the course of the transition to domestic funding, the coverage, scope and quality may decrease. There is a need to conduct gender-disaggregated analysis to measure the effect of this transition to domestic funding on women who use drugs. Such an analysis could show if national HIV strategic plans set any targets for women who use drugs and if governmental procurement policies for HIV programmes encourage or at least allow the allocation of funding for gender-sensitive services.

\section{Conclusion}

Women who use drugs in EECA are not invisible to health services. However, the intentions of the state institutions are more oriented at surveillance and control rather than at treatment and support. Avoiding services is often a rational choice that women take under the pressure of criminalisation, police violence and the threat of forced abortion and loss of child custody.

Community-led harm reduction programmes are best positioned to establish connections with women who inject drugs and link them with sexual and reproductive health, STI and hepatitis C services and OST. But simple referral to services is not enough: women need special access programmes that are designed to address their needs, provide free-of-charge services and ensure the protection of their safety and confidentiality of their personal data. 